\begin{tabular}{|c|c|}
\hline \multirow{3}{*}{ 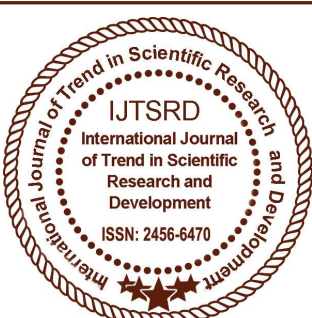 } & $\begin{array}{l}\text { International Journal of Trend in Scientific } \\
\text { Research and Development (IJTSRD) }\end{array}$ \\
\hline & International Open Access Journal \\
\hline & ISSN No: 2456 - 6470 | www.ijtsrd.com | Volume - 2 | Issue -5 \\
\hline
\end{tabular}

\title{
Microcontroller-Based Temperature and pH Measuring System
}

\author{
Cho Cho Myint \\ Lecturer, Department of Natural Science \\ University of Computer Studies, Mandalay, Myanmar
}

\begin{abstract}
Increase in temperature may also lead to an increase in the number of ions in solution due to the dissociation of molecules. As $\mathrm{pH}$ is a measure of the hydrogen ion concentration, a change in the temperature of a solution will be reflected by a subsequent changein $\mathrm{pH}$. In addition, changes in temperature will also have an influence on the measure in sensor used. The temperature sensor and $\mathrm{pH}$ probe are used in conjunction with the microcontroller circuit to measure various $\mathrm{pH}$ levels and temperature ranges. The Liqid Cristal Display (LCD) module is interfaced to display the measured results. Several different testing methods are available for measuring temperature values. For measurement of the temperature values, it is crucial to choose the right DS18B20 Digital Temperature Sensor. A $\mathrm{pH}$ meter measures the potential difference (in $\mathrm{mV}$ ) between the electrodes and converts it to a display of $\mathrm{pH}$.
\end{abstract}

Keywords: PIC16F887microcontroller, $p H$ sensor, temperature sensor, The Liqid Cristal Display (LCD) module.

\section{INTRODUCTION}

Water quality testing is an important part of environmental monitoring. Accurate $\mathrm{pH}$ measurement is required by adjusting the $\mathrm{pH}$ before sending it to the community sewer system. ("Definition of $\mathrm{pH}$ and $\mathrm{pH}$ Testing Tools," n.d.).

Almost all processes containing water have a need for $\mathrm{pH}$ measurement. Most living things depend on a proper $\mathrm{pH}$ level to sustain life. This value is typically between 5 and $9 \mathrm{pH}$, but can vary from area to area.

The photograph of the KADY $\mathrm{pH}$ tester / meter, Model - MT8060, is shown in Figure1.

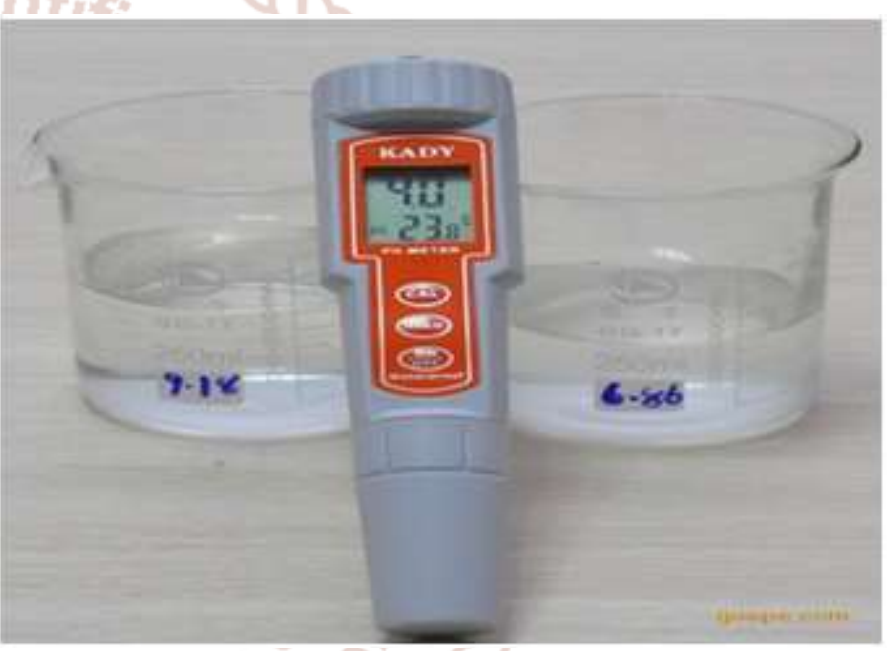

Figure: $1 \mathrm{KADY}$ pH meter, Model - MT80

\section{The Block Diagram of the Whole System}

The block diagram of the constructed system is shown in Figure 2. It consists of five main blocks. The $\mathrm{pH}$ sensor, temperature sensor, microcontroller circuit, The Liqid Cristal Display-LCD module and power supply circuit. The $\mathrm{pH}$ sensor (probe) detects the $\mathrm{pH}$ level of a liquid and produces a small voltage. The voltage is amplified and sent to the microcontroller circuit. The temperature sensor is used to measure the temperature of a liquid. Measured data is sent to the microcontroller circuit. The microcontroller circuit processes on measured data and then sent to the The Liqid Cristal Display-LCD module. The power supply circuit is used to supply necessary voltages to other sections. 


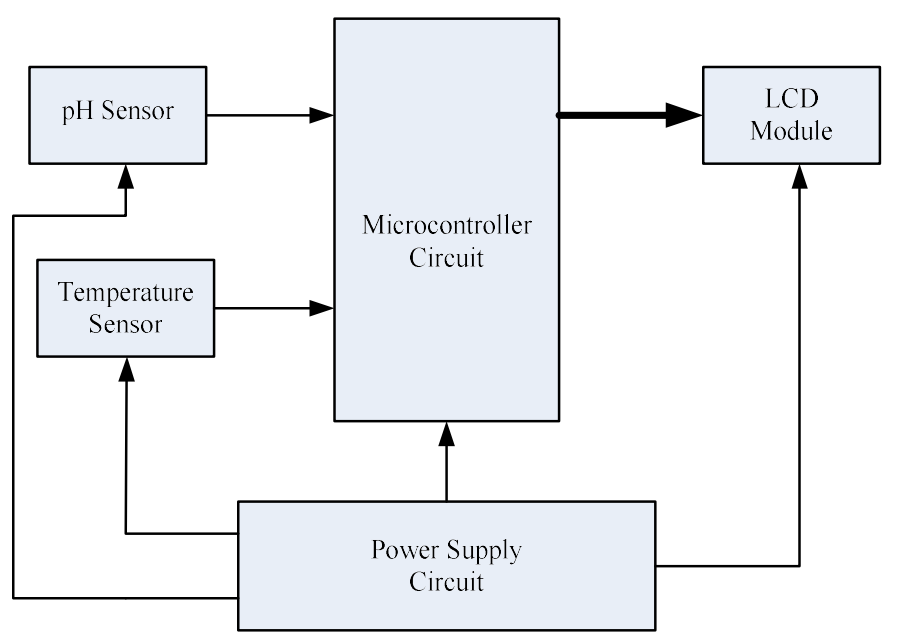

Figure: 2 the block diagram of the whole system

\section{The pH Probe}

The $\mathrm{pH}$ probe is an essential component in the measurement of the $\mathrm{pH}$ level ("PH Electrode Probe BNC Connector for Aquarium PH Control Meter Sensor," 2016). For optimal $\mathrm{pH}$ measurement it is crucial to choose the right $\mathrm{pH}$ probe for each application. The most important sample criteria are: chemical composition, homogeneity, temperature, process pressure, $\mathrm{pH}$ range and container size. The $\mathrm{pH}$ probe (Riddle, 2013) used in this research work is shown in Figure 4. The ideal $\mathrm{pH}$ probe output at different temperatures is shown in figure 5 .

\section{DS18B20 Digital Temperature Sensor}

The DS18B20 digital provides 9-bit to 12-bit Celsius temperature measurements. The DS18B20 communicates over a 1 -Wire bus that by definition requires only one data line (and ground) for communication with a central microprocessor. Each DS18B20 has a unique 64-bit serial code, which allows multiple DS18B20s to function on the same 1Wire bus. Thus, it is simple to use one microprocessor to control many DS18B20s distributed over a large area.

The DS18B20 output temperature data is calibrated in degrees Celsius; for Fahrenheit applications, a lookup table or conversion routine must be used. The temperature data is stored as a 16-bit sign-extended two's complement number in the temperature register. The sign bits ( $\mathrm{S}$ ) indicate if the temperature is positive or negative: The DS18B20 can be powered by an external supply on the VDD pin, or it can operate in "parasite power" mode, which allows the DS18B20 to function without a local external supply. Parasite power is very useful for applications that require remote temperature sensing or that is very space constrained. The photograph of the DS18B20 digital temperature sensor is shown in Figure 3.

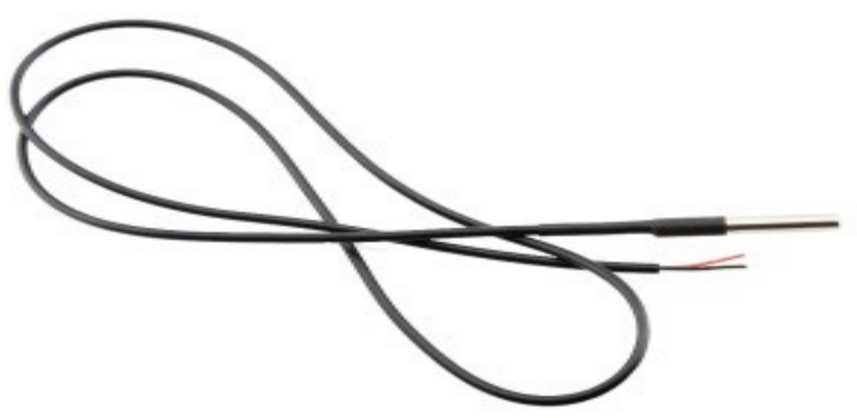

Figure:3 DS18B20 Digital Temperature Sensor

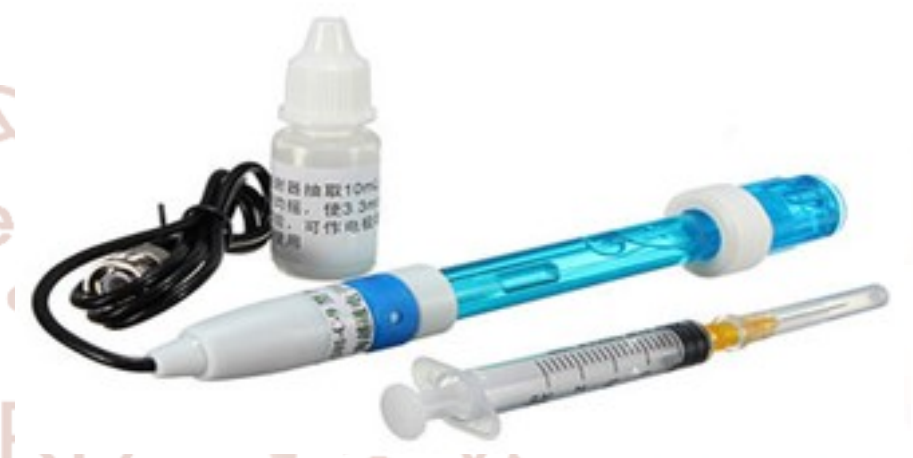

Figure: 4 The $\mathrm{pH}$ electrode probe with $\mathrm{BNC}$ connector

Ideal $\mathrm{pH}$ probe output

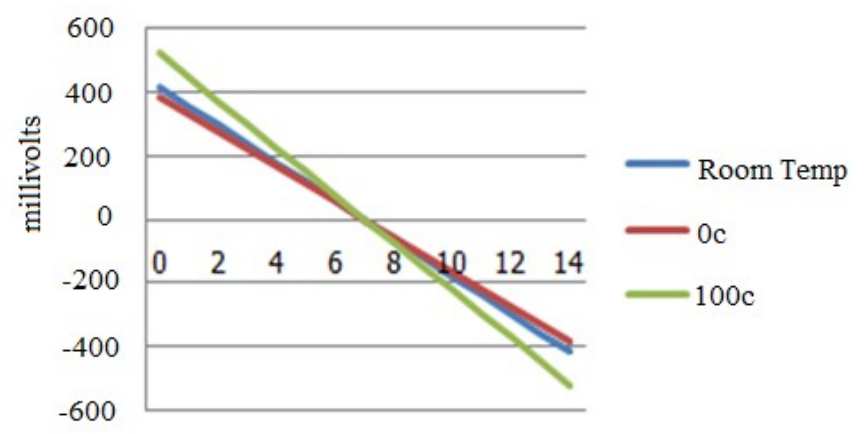

Figure: 5 the ideal $\mathrm{pH}$ probe output at different temperatures

\section{PIC16F887 Hardware}

The microcontroller is simply a computer on a chip. It is one of the most important developments in electronics since the invention of the microprocessor itself. It is essential for the operation of devices such as mobile phones, DVD players, video cameras, and most self-contained electronic systems. The small Liquid Crystal Display screen is a good clue to the presence of an MCU (Microcontroller unit) it needs a programmed device to control it. Working sometimes with other chips, but often on its own, the MCU provides the key element in the vast range of small, programmed devices of which are now common place. 


\section{PIC16F887 Architecture}

Microcontrollers contain all the components required for a processor system in one chip: a CPU, memory and input, output. A complete system can therefore be build using one MCU chip and a few input, output devise such as a keypad, display and other interfacing circuits (Bates, 2013).

\section{PIC16F887 Pin Out}

PICF16887 chip can be obtained in different packages, such as convention 40-pin DIP (Dual In-
Line Package), square surface mount or socket format. The PIC16F887 is the 14-bit instruction word mid-range microcontroller from the Microchip Technology. The PIC microcontroller architecture is based on RISC (Reduced Instruction Set Computer) instruction set (Ibrahim, 2006). The PIC16F887 is a 40-pin device and is one of the popular microcontrollers used in complex applications. The pin configuration of the PIC16F887 microcontroller(Ibrahim, 2008) is shown in Figure 6.

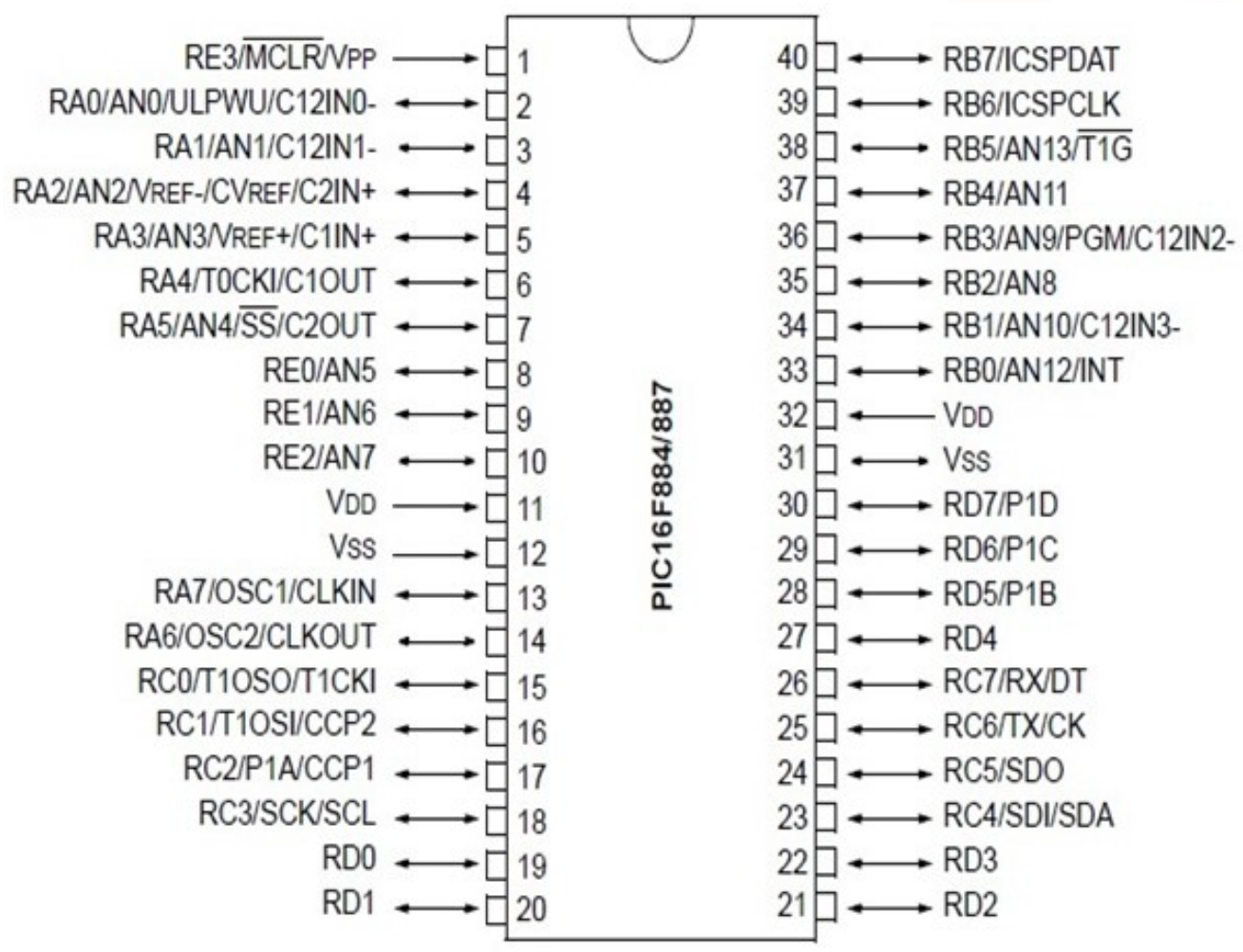

\section{System Software}

Figure: 6 the pin configuration of the PIC16F887 microcontroller
In this project two types of softwares are used.

$>$ Software for micro c programming

$>$ LABVIEW

\section{Liquid Crystal Display (LCD)}

LCDs are alphanumeric displays which are frequently used in microcontroller-based applications. Some of the advantages of LCDs are their low cost and low power consumption. LCDs are ideal in low-power, battery- operated portable applications.

There are basically two types of LCDs as far as the interface technique is concerned: parallel LCDs and serial LCDs. Parallel LCDs are connected to the microcontroller I/O ports using 4 or 8 data wires and data is transferred from the microcontroller to the LCD in parallel form.
These modules has built-in controller, driver, character generator $\mathrm{RAM} / \mathrm{ROM}$. It is capable of displaying two lines of 16 characters. The LCD module provides 4-bit or 8-bit parallel interfaces and writes data directly. The LCD module conforms to standard eight-data lines, three control lines and five power lines.

The connections are laid out a single row of 16 pins. Pin 1 and Pin 2 are the power supply lines, $V_{S S}$ and $\mathrm{V}_{\mathrm{DD}}$. The $\mathrm{V}_{\mathrm{DD}}$ pin is connected to the positive supply and $\mathrm{V}_{\mathrm{SS}}$ to the $0 \mathrm{~V}$ supply or ground. $\mathrm{V}_{\mathrm{EE}}$ or $\mathrm{V}_{0}$ used to alter the contrast of the display. Ideally this pin connected to a variable resistor. The pin description of the $16 \times 2$ line LCD module is shown in Figure 7. 


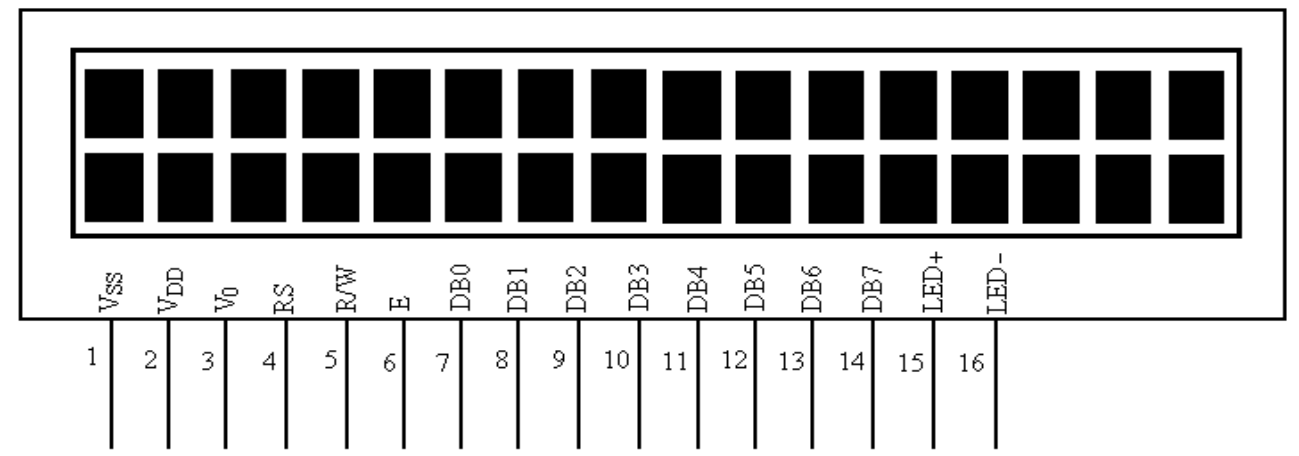

Figure: 7 the pin description of the $16 \times 2$ line Liquid Crystal Display (LCD) module

\section{Design and Construction}

Temperature monitoring system is designed and constructed using a $\mathrm{pH}$ probe, amplifier circuit, DS18B20 one wire temperature sensor, PIC 16F887 microcontroller circuit, $16 \times 2$ line LCD module and power supply circuit. The $\mathrm{pH}$ probe detects the $\mathrm{pH}$ level of the liquids. The probe acts as a small voltage cell and produces small voltage at the BNC cable output. The output signal from the probe is too small to directly interface with the ADC circuit of the microcontroller. Therefore small signal amplifier circuit is used to amplify the signal from the probe. The amplifier circuit is shown in Figure 9. The IC1 and IC2 used in this circuit are two of the operational amplifiers. The IC in the circuit is connected as inverting buffer circuit. The output from the $\mathrm{pH}$ probe is connected with the inverting terminal of the IC1. Non inverting input is directly connected with the

output. IC 2 is the non-inverting amplifier circuit. The resistors at pin 6 input pin and between pin 6 and pin 7 determine the gain of the amplifier. The $100 \mathrm{~K}$ preset reset resistor adjusts the signal level. The $5 \mathrm{~K}$ preset resistor at the output of the amplifier is used to adjust the amplitude of the output signal. The output signal from the amplifier circuit is sent to the ADC input (RA0) of the PIC 16 F887 microcontroller circuit. The complete circuit diagram of the constructed system is shown in Figure 8.

The output of the DS1820 temperature sensor is connected with the RE2 pin of the microcontroller. The port $\mathrm{B}$ pins (RB0 - RB5) of the microcontroller are connected with the RS, E, D4, D5, D6 and D7 pins of the $16 \times 2$ line LCD module, respectively. Measured values are displayed on the LCD module.

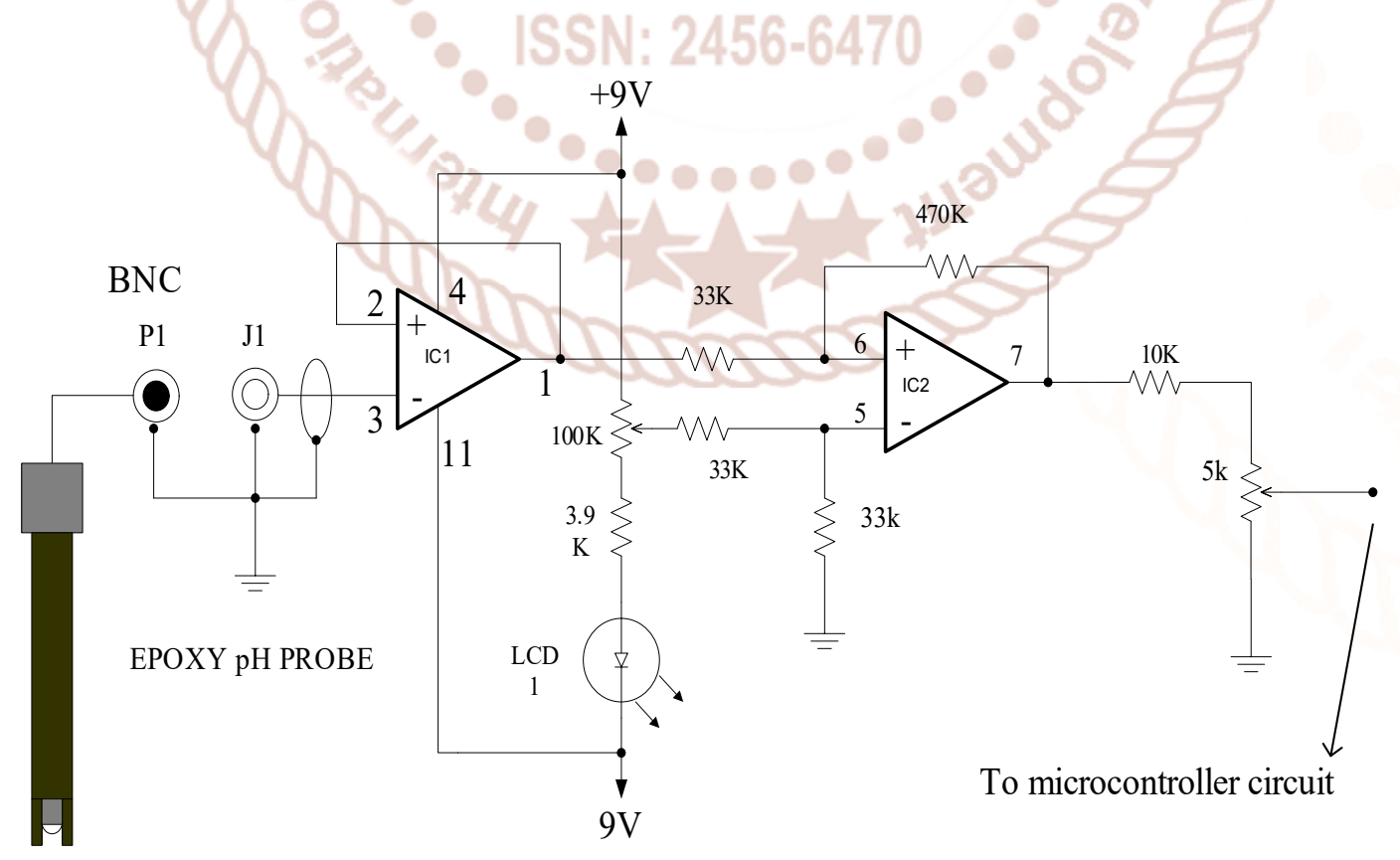

Figure: 8 The amplifier circuit for the $\mathrm{pH}$ probe. 


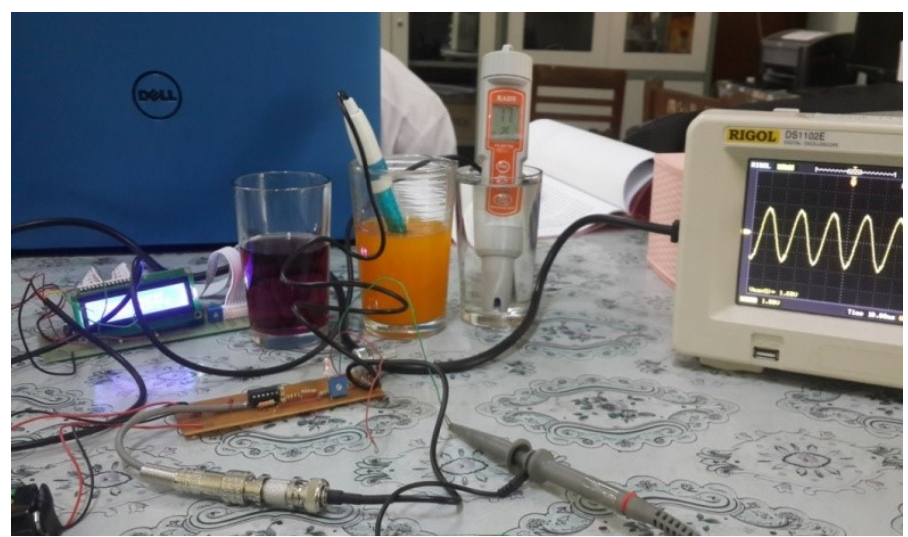

Figure: 9 the photograph showing the temperature measuring circuit and various sample liquids

\section{Results and Discussion}

Microcontroller based $\mathrm{pH}$ level and temperature monitoring system is designed and constructed using a $\mathrm{pH}$ probe, amplifier circuit, DS18B20 one wire temperature sensor, PIC 16F887 microcontroller circuit, $16 \times 2$ line The Liqid Cristal Display (LCD) module and power supply circuit. The $\mathrm{pH}$ probe detects the $\mathrm{pH}$ level of the liquids. The probe acts as a small voltage cell and produces small voltage at the BNC cable output. The output signal from the probe is too small to directly interface with the ADC circuit of the microcontroller. Therefore small signal amplifier circuit is used to amplify the signal from the probe. In pure water, $\mathrm{pH}$ reading is in the range of 5.5-6.9 and voltage signal is $700-720 \mathrm{mV}$. In coca, $\mathrm{pH}$ reading is 2-3 and voltage signal is $620-640 \mathrm{mV}$. In salt water, $\mathrm{pH}$ reading is $9-10$ and voltage signal is $780-800 \mathrm{mV}$.

\section{Conclusion}

Temperature sensor circuit and the $\mathrm{pH}$ sensor circuit can be assembled together with constructed microcontroller circuit. The PC interface circuit can also be constructed to monitor the measured quantities of the liquid in graphical form. Moreover the other quantities of liquid such as conductivity, salinity can be attempted to measure by using Lab make sensors.

\section{REFERENCES}

1. Bates, M. P. (2013). Interfacing PIC Microcontrollers: Embedded Design by Interactive Simulation (2nd Edition). Newnes. Retrieved from https:// books.google.com/ books? isbn=0080993729, on March 172018 .

2. Definition of $\mathrm{pH}$ and $\mathrm{pH}$ Testing Tools. (n.d.). Retrieved from http://www.benmeadows.com, on April 52018.

3. Ibrahim, D. (2006). PIC BASIC PROJECTS: 30 Project Using PIC BASIC and PIC BASIC PRO. UK: Elsevier's Science \&Technology.

4. Ibrahim, D. (2008). Advanced PIC Microcontroller Project in C (First Edition).

5. Riddle, P. (2013). $\mathrm{pH}$ meter and their electrodes :calibration, maintenance and use, 202205.

6. Wilde, F. D., \& Gibs, J. (n.d.). Turbidity. In U.S. Geological Survey TWRI Book. CRC Press Taylor and Franics Group. Retrieved from https:// water.usgs.gov/ owq/ FieldManual/ Chapter6/Archive/6.7/Section6.7.pdf, on March 172018

7. www.maximintegrated.com,

DS18B20, Programmable Resolution 1-Wire Digital Thermometer, 2015 Maxim Integrated Products, Inc. 